\title{
Valorization of crude glycerol into citric acid and malic acid by Yarrowia lipolytica
}

\author{
Xiujuan Qian ${ }^{\mathrm{a}, 1}$, Ning Xu ${ }^{\mathrm{a}, 1}$, Yiwen Jing ${ }^{\mathrm{a}}$, Meng Song ${ }^{\mathrm{a}}$, Jie Zhou ${ }^{\mathrm{a}}$, Weiliang Dong ${ }^{\mathrm{a}, \mathrm{b}}$, \\ Fengxue Xin ${ }^{\mathrm{a}, \mathrm{b}}$, Wenming Zhanga,b*, Min Jiang ${ }^{\mathrm{a}, \mathrm{b} *}$, and Katrin Ochsenreither ${ }^{\mathrm{c}}$
}

aState Key Laboratory of Materials-Oriented Chemical Engineering, College of Biotechnology and Pharmaceutical Engineering, Nanjing Tech University, Nanjing, P. R. China

bJiangsu National Synergetic Innovation Center for Advanced Materials (SICAM), Nanjing Tech University, Nanjing, P. R. China

'Institute of Process Engineering in Life Sciences, Section II: Technical Biology, Karlsruhe Institute of Technology, Fritz-Haber-Weg4, 76131 Karlsruhe, Germany

*Corresponding authors: A/Prof. Wenming Zhang, zhangwm@njtech.edu.cn; Prof.

Min Jiang, bioengine@njtech.edu.cn

State Key Laboratory of Materials-Oriented Chemical Engineering, College of Biotechnology and Pharmaceutical Engineering, Nanjing Tech University, Puzhu South Road 30\#, Nanjing 211816, P. R. China.

${ }^{1}$ These authors contributed equally to this work 
Table S1. Optimization of substrates concentration

\begin{tabular}{|c|c|c|}
\hline Substrate types & Substrates & Investigated concentration $(\mathrm{g} / \mathrm{L})$ \\
\hline \multirow{2}{*}{$\mathrm{C} 1$} & Methanol & $4,7,10,20,30$ \\
\hline & Formate & $4,7,10,20,30$ \\
\hline \multirow{2}{*}{$\mathrm{C} 2$} & Ethanol & $5,10,15,20,30$ \\
\hline & Acetate & $10,20,30$ \\
\hline \multirow{2}{*}{$\mathrm{C} 3$} & Glycerol & $40,60,80$ \\
\hline & Crude glycerol & $20,40,60,80$ \\
\hline \multirow{4}{*}{ Monosaccharide } & Galactose & $20,40,60,80$ \\
\hline & Xylose & $20,40,60,80$ \\
\hline & Glucose & $40,60,80$ \\
\hline & Fructose & $40,60,80$ \\
\hline \multirow{3}{*}{ Disaccharide } & Lactose, Cellobiose, & $20,40,60,80$ \\
\hline & Maltose & $20,40,60,80$ \\
\hline & Sucrose & $40,60,80$ \\
\hline \multirow{3}{*}{ Polysaccharide } & Starch, Cellulose, & $20,40,60,80$ \\
\hline & Inulin & $20,40,60,80$ \\
\hline & Soybean oil & $40,60,80$ \\
\hline \multirow[t]{2}{*}{ Oils } & Rapeseed oil & $40,60,80$ \\
\hline & Corn oil & $40,60,80$ \\
\hline \multirow{2}{*}{ Alkanes } & Hexane & $5,10,15,20$ \\
\hline & Hexadecane & $5,10,15,20$ \\
\hline
\end{tabular}


(a)

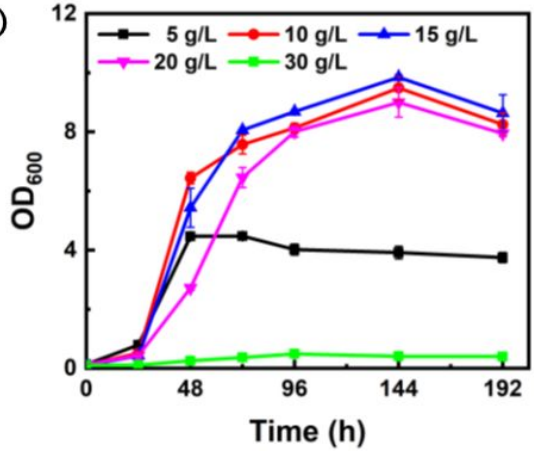

(b)

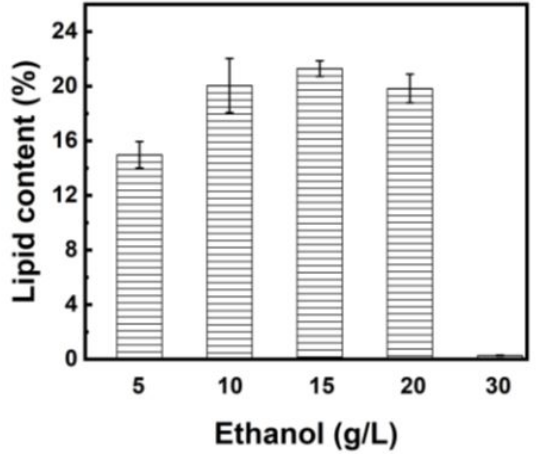

Fig S1. Cell growth and lipids accumulation of Y. lipolytica W29 when different concentrations of ethanol was used as carbon source
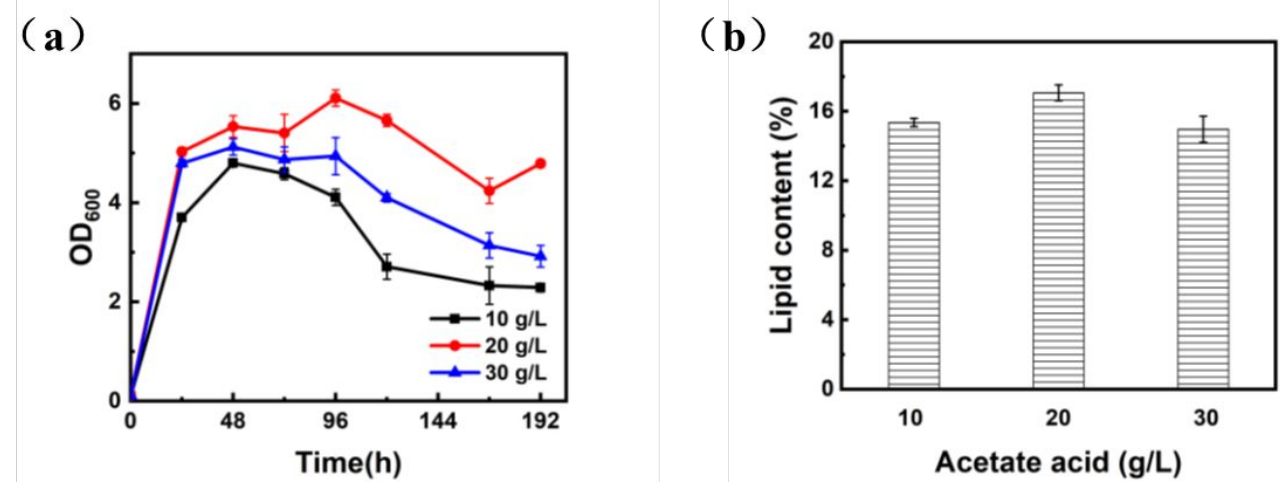

Fig S2. Cell growth and lipids accumulation of Y. lipolytica W29 when different concentrations of sodium acetate was used as carbon source

(a)

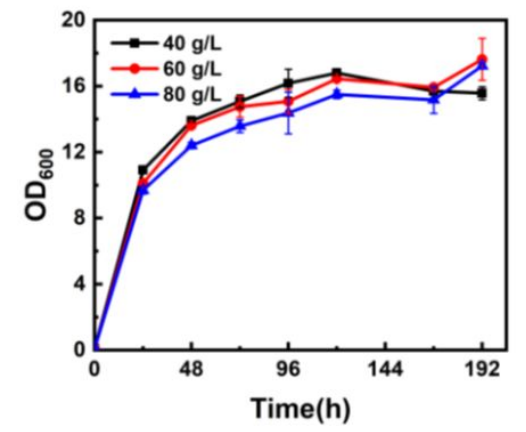

(b)

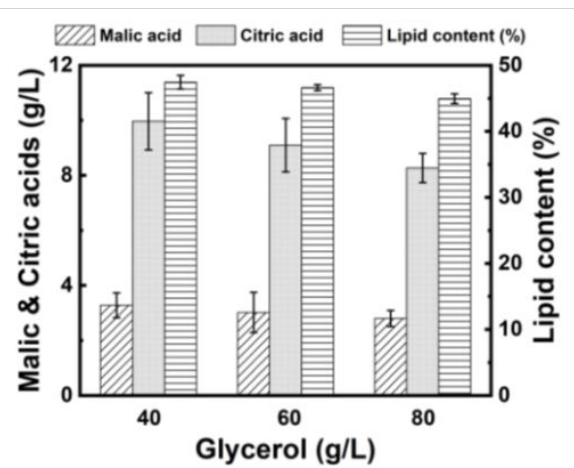

Fig S3. Cell growth, organic acids production and lipids accumulation of Y. lipolytica W29 when different concentrations of glycerol was used as carbon source 
(a)

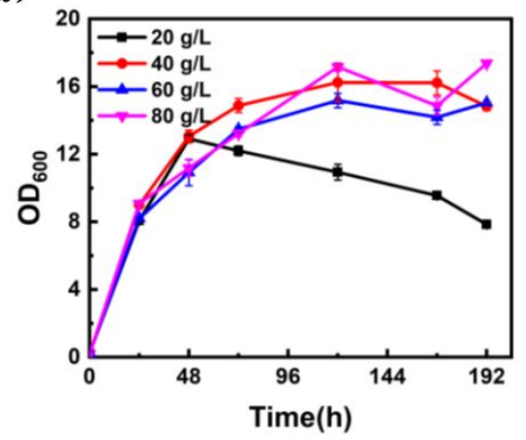

(b)

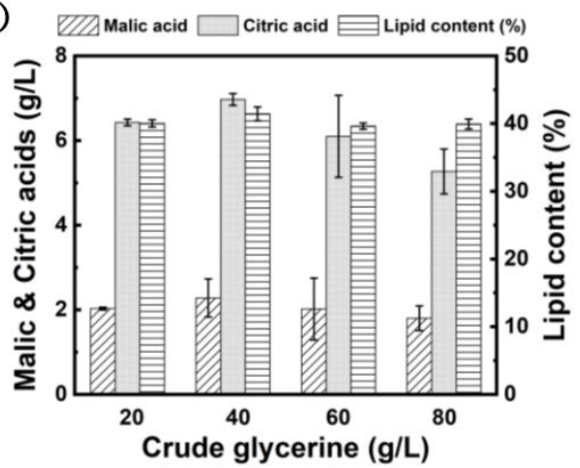

Fig S4. Cell growth, organic acids production and lipids accumulation of Y. lipolytica W29 when different concentrations of crude glycerol was used as carbon source

(a)

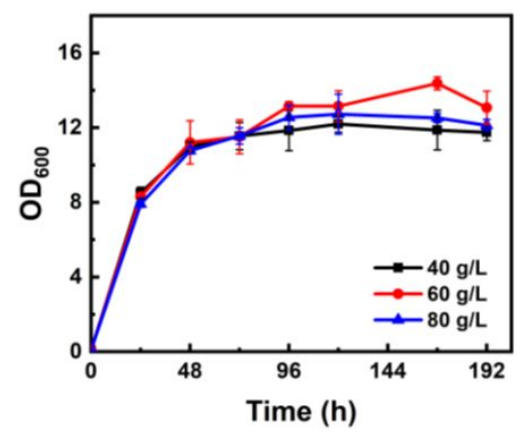

(b)

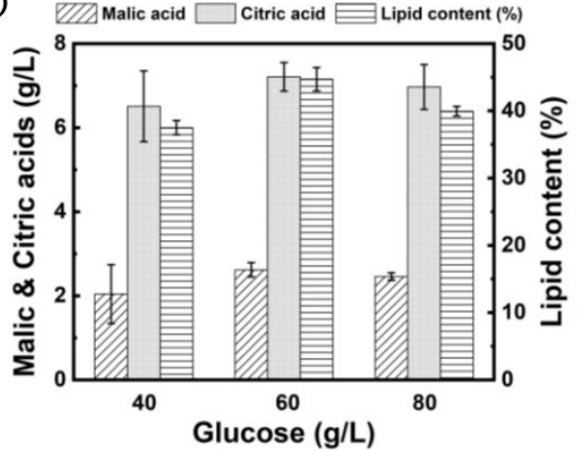

Fig S5. Cell growth, organic acids production and lipids accumulation of $Y$. lipolytica W29 when different concentrations of glucose was used as carbon source

(a)

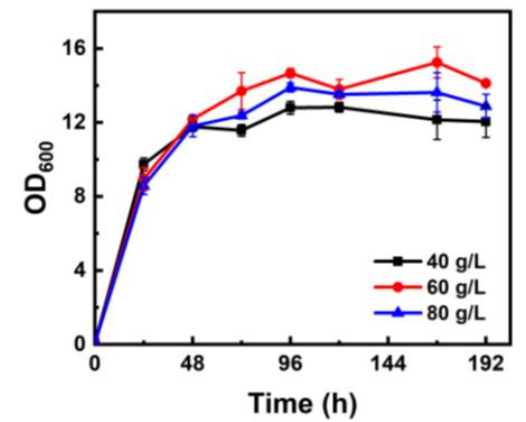

(b)

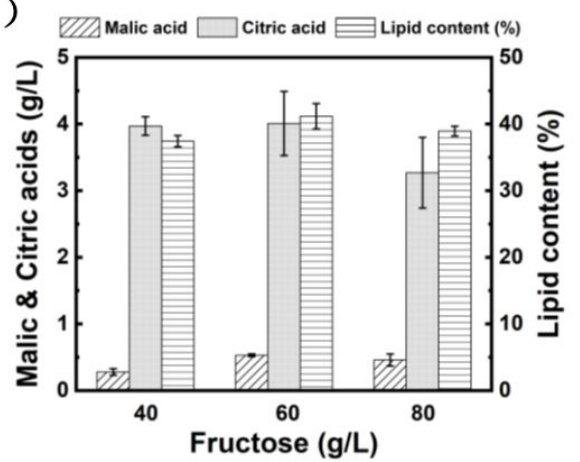

Fig S6. Cell growth, organic acids production and lipids accumulation of Y. lipolytica W29 when different concentrations of fructose was used as carbon source 
(a)

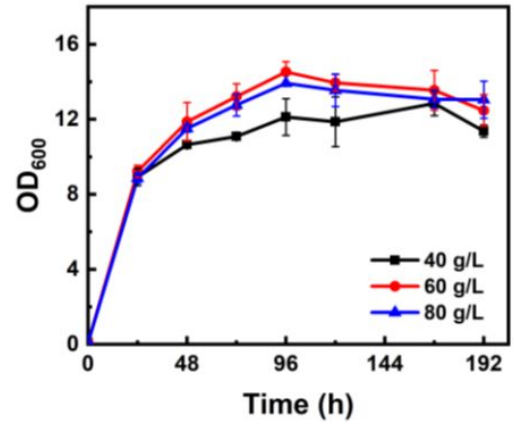

(b)

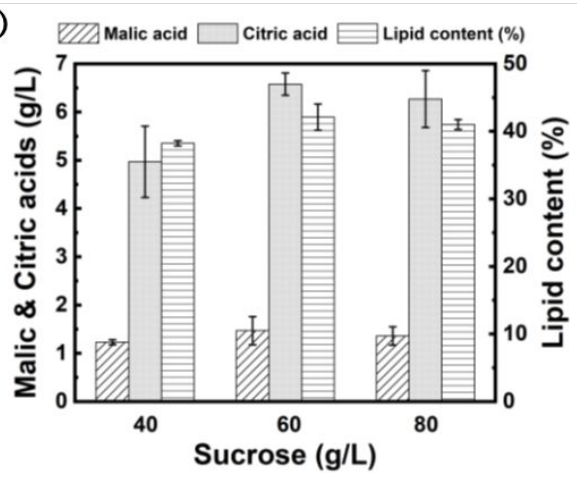

Fig S7. Cell growth, organic acids production and lipids accumulation of Y. lipolytica

W29 when different concentrations of sucrose was used as carbon source

(a)

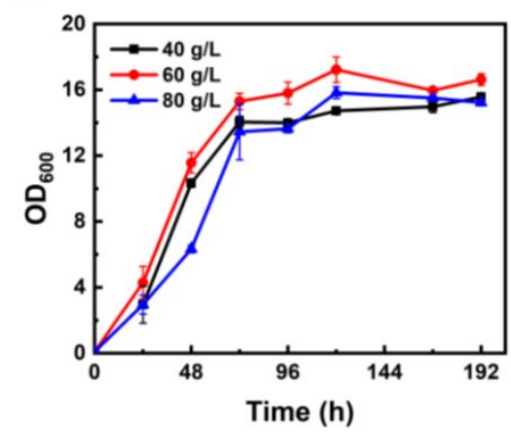

(b)

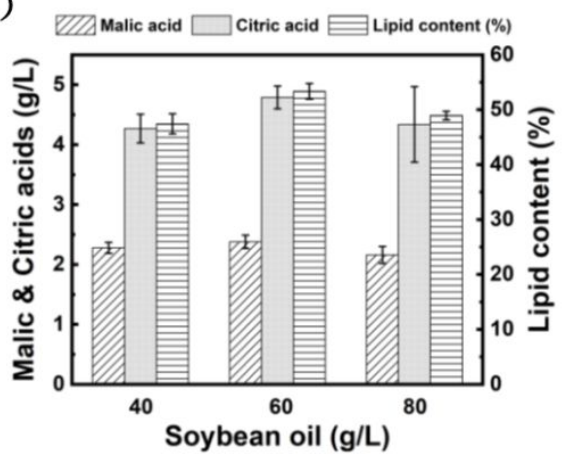

Fig S8. Cell growth, organic acids production and lipids accumulation of $Y$. lipolytica

W29 when different concentrations of soybean oil was used as carbon source

(a)

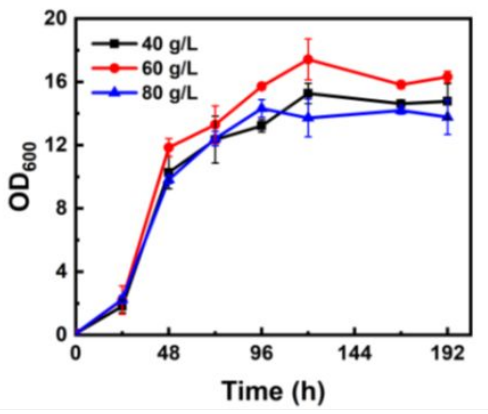

(b)

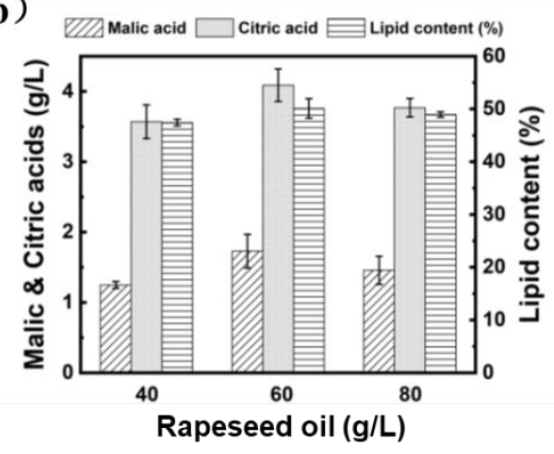

Fig S9. Cell growth, organic acids production and lipids accumulation of Y. lipolytica W29 when different concentrations of rapeseed oil was used as carbon source 
(a)

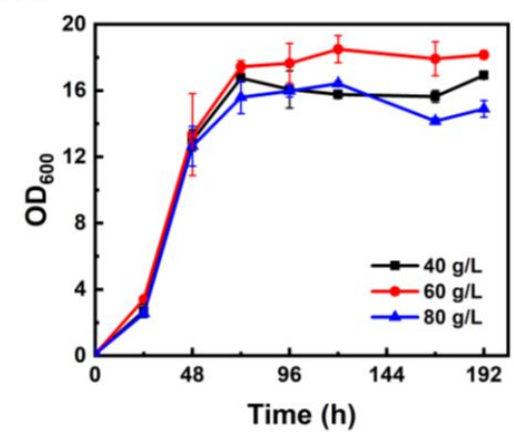

(b)

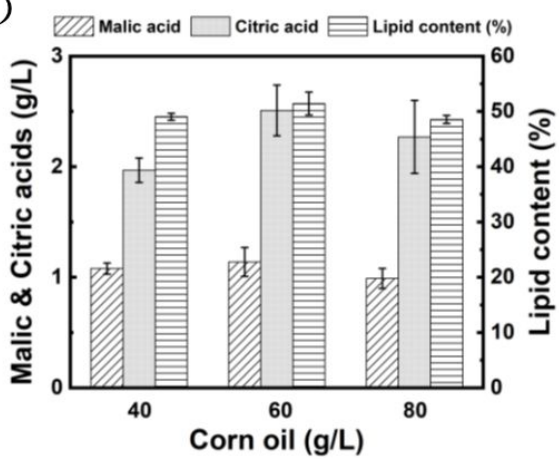

Fig S10. Cell growth, organic acids production and lipids accumulation of $Y$. lipolytica W29 when different concentrations of corn oil was used as carbon source

(a)

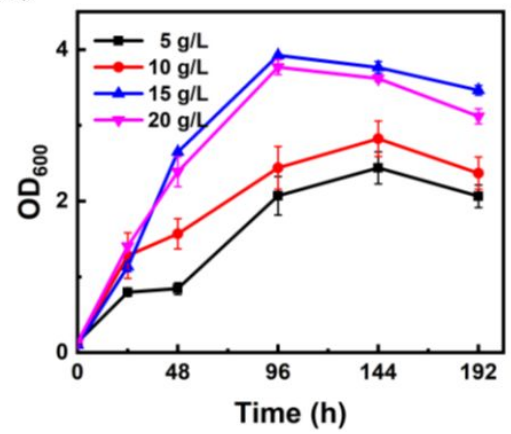

(b)

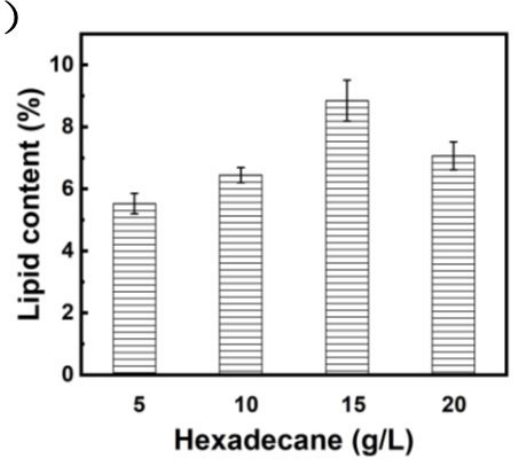

Fig S11. Cell growth and lipids accumulation of Y. lipolytica W29 when different concentrations of hexadecane was used as carbon source 